DOI: $10.52950 / E S .2021 .10 .2 .006$

\title{
EFFECTS OF DEMOGRAPHIC STRUCTURE IN GROWTH ACCOUNTING AND LABOUR MARKET DECOMPOSITIONS
}

\section{PETR MALECEK}

\begin{abstract}
:
Impact of demographic structure on labor market and macroeconomic aggregates might be pronounced in some countries. Despite this fact, only a handful of approaches dealing with quantifications such effects have been derived so far. The aim of this paper is therefore to fill this methodological gap and to introduce methodological approaches for capturing changes in demographic structure, with many applications in growth accounting and labor market decompositions. Firstly, a novel additive decomposition will be presented, as an alternative to traditional models using fixed population weights. This will be followed by the presentation of a multiplicative decomposition, which can be applied to all kinds of growth accounting exercises based on multiplicative identities.
\end{abstract}

\section{Keywords:}

demographics; demographic structure; labour market; decomposition; growth accounting

JEL Classification: J11, C02

\section{Authors:}

PETR MALECEK, Alpiq Energy SE and University of Economics and Business, Czech Republic, Email: petrxmalecek@gmail.com

\section{Citation:}

PETR MALECEK (2021). EFFECTS OF DEMOGRAPHIC STRUCTURE IN GROWTH ACCOUNTING AND LABOUR MARKET DECOMPOSITIONS. International Journal of Economic Sciences, Vol. X(2), pp. 104-114., 10.52950/ES.2021.10.2.006 


\section{Introduction and literature review}

When examining age-specific employment (or activity) rates, these typically show a distinctive "inverted U-shaped" pattern, as seen in Figure 1 in the case of France. This picture is widespread throughout the world, see e.g. Branson and Wittenberg (2007). Young persons exhibit relatively high inactivity rates due to education; on the other side of the age spectrum, elderly persons typically experience higher inactivity rates due to either disability or old-age retirement. The change of the aggregate employment (or activity) rate is then an outcome of two effects. First, quite straightforwardly, it can be subject to changes in age-specific employment rates. On the top of that, even when these rates are constant, the aggregate measure can change on the back of alternations in demographic structure. As an example, in case the relative weight of prime age population (i.e. from 25 to 54 years) would increase, the aggregate employment rate of an economy exhibiting such typical inverted Ushaped pattern would increase. These two effects get about simultaneously, so that even if the aggregate employment (or activity) would be constant, there may be significant underlying movements in opposite directions, with important consequences for interpreting the results.

Fig. 1: Employment rates of selected population groups in France (2019)

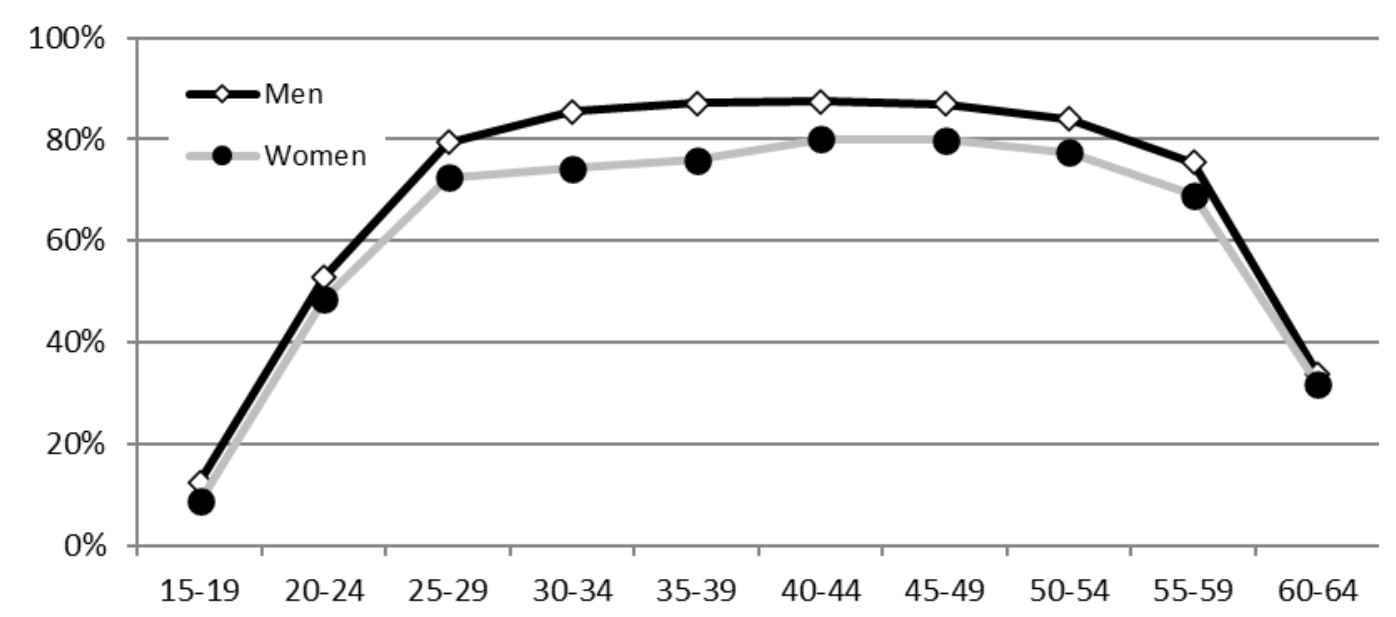

Source: Eurostat

The idea of taking into account effects of demographic structure when analyzing macroeconomic phenomena goes back as far as Perry (1970), who constructed weighted unemployment rate according to age and sex in order to better capture labor market tightness. Hours worked and average earnings were picked as weights for this exercise. Following this seminal paper, other authors term similar weighing as a "Perry-weighted" measure, see e.g. Ball and Mankiw (2002) who use time-invariant weights in order to show how the overall unemployment rate would have evolved if sizes of population groups did not change; Gordon (1997) applied Perry's method for calculating the time-varying NAIRU. The notion of fixing demographic weights in order to disentangle age and other effects was developed by Shimer (1999), and has been since used by many authors, e.g. by Katz and Krueger (1999) or Barwell (2000). Shimer defines two distinct measures of unemployment. First, the changes in "genuine" unemployment rate refer to that with fixed demographic weights at a given 
time in the past $(t 0)$ and age-specific unemployment rates $\left(U_{t, i}\right)$ are allowed to move freely.

$$
U_{G}=\sum_{i=1}^{n} w_{t 0, i} U_{t, i}
$$

Weights are simply defined as a share of active persons in a given age cohort to all active persons.

$$
w_{t, i}=\frac{A_{t, i}}{\sum_{i=1}^{n} A_{t, i}}
$$

Next, the changes in unemployment rate, with constant age-specific unemployment rates at a given time in the past, are referred to as "demographic".

$$
U_{D}=\sum_{i=1}^{n} w_{t, i} U_{t 0, i}
$$

This methodology has been used for many purposes. As an example, Shimer (1999) found out that demographics play an important role in explaining changes in the aggregate unemployment rate. Barwell (2000) used changing cohort weights argument to support the apparent decline in the natural rate of unemployment, by linking this outcome to the falling share of young persons.

Notably, these decompositions may not only entail demographic effects, Summers (1986) argued that the most important adjustment for changes in the composition of the labor force involves education and found out that the compositional effects of an increasing overall level of educational attainment offset the adverse effects of changes in age and sex composition in the 1960s and 1970s in the United States.

An important assumption of these quantifications is that demographics do not affect disaggregate unemployment rates. As also argued, if we could divide the population into more age groups, logic and evidence suggest that we would attribute more of the motion of an aggregate measure to the changing age structure of the labor force (see further sections for empirical investigation). Regarding these effects, there has been mixed evidence. Shimer (2001) found out that an increase in the youth share of working age population reduces the youth unemployment rate and that the effect on the prime age unemployment rate is even larger in magnitude, having crutial impact on life style changes and influencing other sectors of the economy (see Hromada et al. 2021, for real estate market implications or implications for regional disparities on the labour market in Čermáková et al., 2019). One possible explanation is that young workers migrate to regions with low unemployment rates (Kaderabkova et al., 2020). 
On the other hand, these results are sharply in contrast with Korenman and Neumark's (2000) conclusion from their review of the literature that "there seems to be evidence of an adverse effect of cohort size on youth unemployment, employment, and wages across a number of countries."

In general, measuring impacts of demographic structure on various macroeconomic aggregates has been a recurring theme in economic literature. Its effects on output have been researched e.g. by Aksoy et al. (2019), by utilizing a panel VAR for OECD countries, effects on specific labour markets by Kotrba et al. (2021), or Neethu et al. (2021) confirming budgetary consequences of migration and its effects on the health sector. Another example is the analysis of impacts of demographic structure on capital accumulation by d'Albis (2007).

\section{Methodology}

This section presents the methodology to decompose labor market aggregates into effects of demographic structure and age-specific effects. First, an additive decomposition technique will be presented, which is an amendment of the Shimer (1999) methodology, useful when analyzing an individual labor market aggregate separately. Next, a multiplicative decomposition will be derived, which can be then utilized within a range of growth accounting frameworks.

\subsection{Additive decomposition}

This methodology is essentially an augmented approach by Shimer (1999), whereas we let the base time to move freely. In all subsequent exercises, we will use the notion of employment rate (a ratio of employed to population), but this methodology applies in the same manner also to other aggregates which utilize fractions, let it be activity rate, unemployment rate etc.

Therefore, the change in employment rate (in percentage points) between time $t$ and $t-1$ (any other time lag can be used) is a sum of differences of age-specific employment rates weighted by their respective shares in total population at time $t-1$, and the sum of differences of such weights, multiplied by age-specific employment rate at time $t$. The first term captures development in specific employment rates (let us call it the "employment effect"), whereas the second term in turn captures changes in demographic structure.

$$
E R_{t}-E R_{t-1}=\underbrace{\sum_{i=1}^{n} w_{t-1, i}\left(E R_{t, i}-E R_{t-1, i}\right)}_{\text {employment effect }}+\underbrace{\sum_{i=1}^{n}\left(w_{t, i}-w_{t-1, i}\right) E R_{t, i}}_{\text {demographic effect }} \text {, where }
$$

$E R_{t}$ denotes the total employment rate: $E R_{t}=\frac{\sum_{i=1}^{n} E_{t, i}}{\sum_{i=1}^{n} P_{t, i}}$, 
$E R_{t, i}$ group-specific employment rates: $E R_{t, i}=\frac{E_{t, i}}{P_{t, i}}$ and

$w_{t, i}$ weights of an $i$-th group in total population: $w_{t, i}=\frac{P_{t, i}}{\sum_{i=1}^{n} P_{t, i}}$.

\subsection{Additive decomposition: the results}

Figure 2 presents an example of such decomposition in the case of France. It is clear that the change in demographic structure contributed negatively to the change of the employment rate. This has been in place especially until to 2011 , largely due to decreasing weight of population aged 25-34, i.e. those with above-average employment rates.

Fig. 2: Additive decomposition of $y-0-y$ change in employment rate in France (in percentage points)

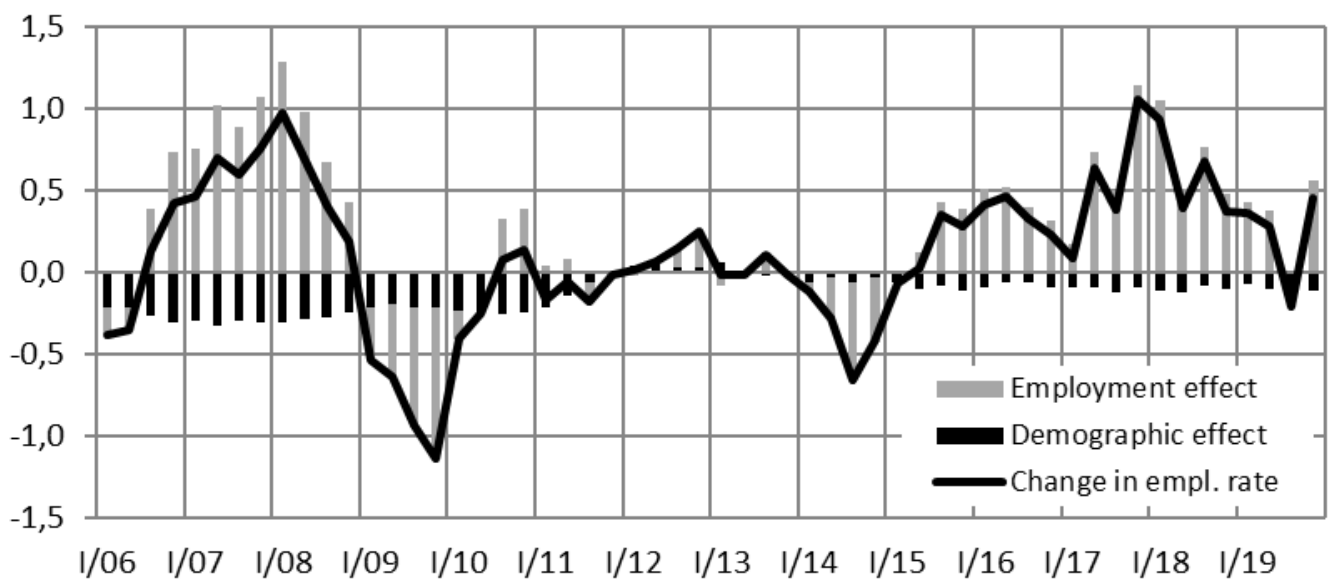

Source: Eurostat, own calculations.

\subsection{Multiplicative decomposition}

In mainstream growth accounting exercises, real GDP is most often disaggregated using multiplication, typically by means of a the copiously utilized Cobb-Douglas production function. For further reference, we will use a rather trivial example of a growth accounting framework; for further discussion see e.g. Mourre (2009), real GDP at time $t$ can being decomposed into real labor productivity, employment rate and total population (see equation below).

$$
G D P_{t}=\frac{G D P_{t}}{E_{t}} \cdot \frac{E_{t}}{P_{t}} \cdot P_{t}
$$

In order to calculate contributions to real GDP growth, this simply involves dividing each component by its value at time $t-1$ and taking natural logarithms. 


$$
\log \left(\frac{G D P_{t}}{G D P_{t-1}}\right)=\log \left(\frac{G D P_{t}}{E_{t}} / \frac{G D P_{t-1}}{E_{t-1}}\right)+\log \left(\frac{E R_{t}}{E R_{t-1}}\right)+\log \left(\frac{P_{t}}{P_{t-1}}\right)
$$

At this stage, we will further disentangle the employment rate term into "pure" employment rate effects and that of demographics. It obviously holds that the growth of employment rate is equal to the sum of weighted cohort-specific employment rates divided by this measure at time $t-1$.

$$
\frac{E R_{t}}{E R_{t-1}}=\frac{\sum_{i=1}^{n} w_{t, i} E R_{t, i}}{\sum_{i=1}^{n} w_{t-1, i} E R_{t-1, i}}
$$

Similarly to the additive decomposition technique, we will then define the "employment effect", capturing genuine changes in cohort-specific employment rates, while keeping the same demographic weights at time $t-1$. The changes in demographic structure are in turned recorded in the "demographic effect", whereas individual employment rates are the same (at time $t$ ), and weights are allowed to change.

$$
\frac{E R_{t}}{E R_{t-1}}=\underbrace{\sum_{i=1}^{n} w_{t-1, i} E R_{t, i}}_{\text {employment effect }} \cdot \underbrace{\sum_{i=1}^{n} w_{t-1, i} E R_{t-1, i}}_{\text {demographic effect }} \cdot \frac{\sum_{i=1}^{n} w_{t, i} E R_{t, i}}{\sum_{i=1}^{n} w_{t, i} E R_{t, i}}
$$

Thus, the employment term in equation 9 can be replaced by the term below.

$$
\log \left(\frac{E R_{t}}{E R_{t-1}}\right)=\underbrace{\log \underbrace{\sum_{i=1}^{n} w_{t-1, i} E R_{t-1, i}}_{\text {demographic effect }}}_{\text {employment effect }}+\underbrace{\log \frac{\sum_{i=1}^{n} w_{t, i} E R_{t, i}}{\sum_{i=1}^{n} w_{t-1, i} E R_{t, i}}}_{\text {i=1 }}
$$

As a result, the simple GDP accounting exercise in equation 8 can be interpreted as decomposition of real GDP growth into real labor productivity, the effect of agespecific employment rates, effects of demographic structure, and the total population size.

It should be emphasized that this decomposition technique is not limited only to the specific case in equation 8 , but can be applied to any multiplicative relationship involving a ratio of a given labour market aggregate to population. Notably, an analysis of conomic growth by means of the Cobb-Douglas production function can be extended in this fashion. There is a vast array of literature in this respect; to pick an example, Čadil (2017), uses inter alia the original form of the Cobb-Douglas function: 


$$
Y_{t}=A_{t} K_{t}^{\alpha} L_{t}^{\beta}
$$

Its dynamic version would then be simply:

$$
\log \frac{Y_{t}}{Y_{t-1}}=\log \frac{A_{t}}{A_{t-1}}+\alpha \log \frac{K_{t}}{K_{t-1}}+\beta \log \frac{L_{t}}{L_{t-1}}
$$

The labour component is then typically understood as either headcount employment or total hours worked. The latter is argued in e.g. Havik et al. (2014); they further split the labour component into working age population, participation rate, unemployment rate and average hours worked. If we then decompose this relationship further using the common definitions for participation rate (a ratio of employed and unemployed to population) and unemployment rate (a ratio of unemployed to active, i.e. employed plus unemployed), we obtain the following proposition.

$$
L_{t}=P_{t} \frac{E_{t}+U_{t}}{P_{t}}\left(1-\frac{U_{t}}{E_{t}+U_{t}}\right) H_{t}
$$

Then, we can as well track the effects of changes in demographic structure of participation rate using the defined identity in equation (12), simply by superseding employement $\left(E_{t}\right)$ by participation $\left(E_{t}+U_{t}\right)$.

To mention other possible applications of equation (12), an analysis of labour market costs, like the one in Kadeřábková and Jašová (2019), can be further enhanced by substituting an employment term in unit labour costs by the identity population times employment rate. Then, equation (12) can be applied to the employement rate and thus enabling the study of impacts of changes in demographic structure on unit labour costs.

\subsection{Multiplicative decomposition: the results}

Turning back to our original example given by equation (8), Table 1 presents the results of growth accounting decomposition in the case of three selected countries: France, Spain and the United States. In France, we can observe a rather long period where demographic structure posed a quite significant drag on growth: 2003-2011 (as already discussed in the section dealing with the additive decomposition technique). Notably, in 2006, the adverse development in demographic structure outweighed positive effects of cohort-specific employment rates. On the other hand, in the case of Spain, the benign development of employment rate in the beginning of the last decade was fostered by positive changes in demographic structure. Lastly, there can be countries where the development in demographic structure during the last years has not played any major role in such exercises, with an example of the United States. Effects of demographic structure have been negative during 2003- 
2012, but contributed to real GDP growth just between -0.1 to -0.2 pps. Obviously, the magnitude of effects in Table 1 differ from those in Figure 2, as the latter is based on a change in log points (i.e. essentially on a growth rate of employment rate) and the former on percentage points change.

Table 1: Results of the growth accounting exercise

France

\begin{tabular}{|c|c|c|c|c|c|c|c|c|c|c|c|c|c|c|c|c|c|}
\hline & 2003 & 2004 & 2005 & 2006 & 2007 & 2008 & 2009 & 2010 & 2011 & 2012 & 2013 & 2014 & 2015 & 2016 & 2017 & 2018 & 2019 \\
\hline dlog (GDP) & 0,8 & 2,8 & 1,6 & 2,4 & 2,4 & 0,3 & $-2,9$ & 1,9 & 2,2 & 0,3 & 0,6 & 1,0 & 1,1 & 1,1 & 2,3 & 1,8 & 1,5 \\
\hline dlog (GDP/E) & $-2,2$ & 2,9 & 0,0 & 1,7 & 0,8 & $-1,0$ & $-2,0$ & 1,8 & 2,2 & 0,3 & 0,7 & $-1,2$ & 1,0 & 0,6 & 1,5 & 0,9 & 1,3 \\
\hline dlog (E/POP) & 1,6 & $-0,8$ & 0,5 & $-0,1$ & 1,0 & 0,9 & $-1,3$ & $-0,2$ & $-0,2$ & 0,2 & 0,0 & $-0,6$ & 0,2 & 0,6 & 0,8 & 0,9 & 0,3 \\
\hline - empl. eff. & 1,9 & $-0,5$ & 1,0 & 0,3 & 1,5 & 1,3 & $-0,9$ & 0,2 & 0,0 & 0,1 & 0,0 & $-0,5$ & 0,4 & 0,7 & 1,0 & 1,1 & 0,5 \\
\hline - dem. eff. & $-0,3$ & $-0,3$ & $-0,5$ & $-0,4$ & $-0,5$ & $-0,4$ & $-0,3$ & $-0,4$ & $-0,2$ & 0,1 & 0,0 & $-0,1$ & $-0,1$ & $-0,1$ & $-0,2$ & $-0,2$ & $-0,2$ \\
\hline dlog (POP) & 1,4 & 0,7 & 1,1 & 0,8 & 0,6 & 0,4 & 0,3 & 0,3 & 0,1 & $-0,2$ & $-0,1$ & 2,8 & $-0,1$ & $-0,1$ & $-0,1$ & $-0,1$ & $-0,1$ \\
\hline
\end{tabular}

Spain

\begin{tabular}{|c|c|c|c|c|c|c|c|c|c|c|c|c|c|c|c|c|c|}
\hline & 2003 & 2004 & 2005 & 2006 & 2007 & 2008 & 2009 & 2010 & 2011 & 2012 & 2013 & 2014 & 2015 & 2016 & 2017 & 2018 & 2019 \\
\hline dlog (GDP) & 2,9 & 3,1 & 3,6 & 4,0 & 3,5 & 0,9 & $-3,8$ & 0,2 & $-0,8$ & $-3,0$ & $-1,4$ & 1,4 & 3,8 & 3,0 & 2,9 & 2,3 & 2,0 \\
\hline dlog (GDP/E) & $-0,9$ & $-0,3$ & $-2,7$ & 0,3 & 0,3 & 1,5 & 3,1 & 2,2 & 0,8 & 1,4 & 1,3 & 0,2 & 0,9 & 0,4 & 0,3 & $-0,3$ & $-0,3$ \\
\hline dlog (E/POP) & 1,8 & 1,6 & 4,0 & 2,3 & 1,2 & $-2,0$ & $-7,3$ & $-1,9$ & $-1,4$ & $-4,0$ & $-1,7$ & 2,1 & 3,3 & 2,9 & 2,5 & 2,1 & 1,5 \\
\hline - empl. eff. & 1,4 & 1,3 & 3,8 & 2,1 & 1,1 & $-2,1$ & $-7,4$ & $-2,1$ & $-1,6$ & $-4,1$ & $-1,7$ & 2,2 & 3,5 & 3,2 & 2,9 & 2,5 & 1,8 \\
\hline - dem. eff. & 0,4 & 0,3 & 0,3 & 0,2 & 0,1 & 0,1 & 0,2 & 0,2 & 0,2 & 0,1 & 0,0 & $-0,1$ & $-0,3$ & $-0,3$ & $-0,4$ & $-0,4$ & $-0,4$ \\
\hline dlog (POP) & 2,0 & 1,8 & 2,3 & 1,5 & 2,0 & 1,5 & 0,3 & $-0,2$ & $-0,2$ & $-0,5$ & $-1,0$ & $-0,9$ & $-0,4$ & $-0,3$ & 0,0 & 0,5 & 0,8 \\
\hline
\end{tabular}

United

States

\begin{tabular}{|c|c|c|c|c|c|c|c|c|c|c|c|c|c|c|c|c|c|}
\hline & 2003 & 2004 & 2005 & 2006 & 2007 & 2008 & 2009 & 2010 & 2011 & 2012 & 2013 & 2014 & 2015 & 2016 & 2017 & 2018 & 2019 \\
\hline $\operatorname{dlog}(G D P)$ & 2,8 & 3,7 & 3,5 & 2,8 & 1,9 & $-0,1$ & $-2,6$ & 2,5 & 1,5 & 2,2 & 1,8 & 2,5 & 2,9 & 1,6 & 2,3 & 2,9 & 2,3 \\
\hline $\operatorname{dlog}(\mathrm{GDP} / \mathrm{E})$ & 2,1 & 2,8 & 1,8 & 1,0 & 0,9 & 0,6 & 1,5 & 3,3 & 1,2 & 0,7 & 1,1 & 1,0 & 1,4 & 0,1 & 1,2 & 1,5 & 1,5 \\
\hline dlog (E/POP) & $-1,0$ & 0,0 & 0,4 & 0,7 & $-0,3$ & $-1,3$ & $-4,7$ & $-1,4$ & $-0,1$ & 0,7 & 0,3 & 1,2 & 0,8 & 0,9 & 1,1 & 0,9 & 0,9 \\
\hline - empl. eff. & $-0,9$ & 0,1 & 0,5 & 0,8 & $-0,1$ & $-1,1$ & $-4,6$ & $-1,3$ & 0,1 & 0,9 & 0,3 & 1,2 & 0,8 & 0,9 & 1,1 & 0,9 & 0,9 \\
\hline - dem. eff. & $-0,1$ & $-0,1$ & $-0,1$ & $-0,1$ & $-0,2$ & $-0,1$ & $-0,1$ & $-0,1$ & $-0,1$ & $-0,2$ & 0,0 & 0,0 & 0,0 & 0,0 & 0,0 & 0,0 & 0,0 \\
\hline dlog (POP) & 1,7 & 1,0 & 1,2 & 1,1 & 1,3 & 0,5 & 0,6 & 0,7 & 0,4 & 0,8 & 0,4 & 0,4 & 0,6 & 0,6 & 0,0 & 0,5 & $-0,1$ \\
\hline
\end{tabular}

Source: Eurostat, OECD, own calculations. 
If warranted, demographic effects can be traced further to individual cohorts. As an example, in the case of France, there has been a decline in shares of cohorts with consistently highest employment rates (aged 25-49), and an increase of relative representation of pre-retirement age cohorts (aged 50-64); both negatively affecting the demographic effect.

\subsection{Several caveats}

It should be noted that this methodology should be excercised with due caution. An important assumption is that demographics do not affect disaggregate employment rates, as discussed e.g. in Shimer (1999). Moreover, decompositions can be quite sensitive to the number of cohorts used calculations, whereas a higher number of cohorts does not necessarily lead to a higher contribution of demographics. Figure 3 shows a sensitivity analysis of the demographic effects in France, depending on the number of cohorts. Four scenarios are presented: the case with 20 cohorts - which has been already shown, i.e. men and women in 5 years' age groups, 10 cohorts - 5 years' groups with no gender distinction, 7 cohorts the age groups 15-24, 25-34, 35-39, 40-44, 45-54, 55-59 and 60-64, and 5 cohorts the age groups 15-24, 25-34, 35-44, 45-54 and 55-64. Not surprisingly, the results with and without gender distinction differ only very slightly, in case demographic patterns for both sexes are very similar, which is the case of France.

Fig. 3: Demographic effect in France (multiplicative decomposition) in relation to the number of age groups used in calculations

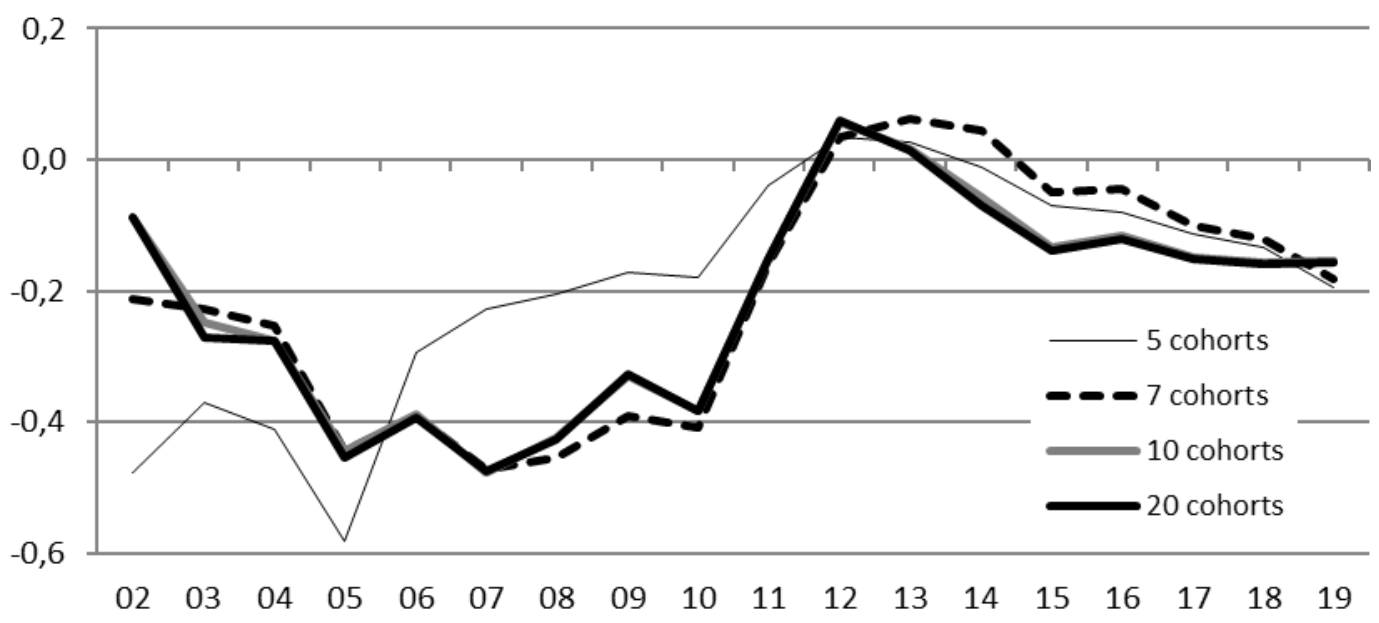

Source: Eurostat, own calculations.

\section{Conclusion}

The aim of this article was to introduce methodologies for capturing changes in demographic structure in labor market decompositions. Two new approaches were derived, first an extension to the already used additive decomposition techniques, and the novel decomposition suitable for multiplicative identities, including the CobbDouglas production function.

It has been shown that in some cases, changes in demographic structure can have important effect on aggregate measures, which was demonstrated in the case of France and Spain. In this respect, accounting for demographics can have important 
policy implications, as it can unravel hidden weaknesses or strengths of a particular labor market in terms of genuine changes in age-specific employment or activity rates.

\section{Acknowledgements}

This research was founded by grant number IP 500040 .

\section{References}

Aksoy, Y., Basso, H. S., Smith, R. P., Grasl, T. (2019). Demographic structure and macroeconomic trends. American Economic Journal: Macroeconomics, Vol. 11, No. 1.

D'Albis, H. (2007). Demographic structure and capital accumulation. Journal of Economic Theory, Vol. 132, No. 1.

Ball, L., Mankiw, N. G. (2002). The NAIRU in Theory and Practice. Journal of Economic Perspectives Vol. 14, No. 4: 115-136.

Barwell, R. (2000). Age structure and the UK unemployment rate. Bank of England Working Papers.

Branson, N., Witternberg, M. (2007). The Measurement of Employment Status in South Africa Using Cohort Analysis, 1994-2004. South African Journal of Economics, Vol. 75, No. 2.

Čadil, J., VItavská K., Krejčí, I., Hartman, D., Brabec, M. (2017). Aggregate producion function and income identity - empirical analysis. International Journal of Economic Sciences Vol. VI, No. 1.

Čermáková, K., Jašová, E. (2019). Analysis of the Negative and Positive Impact of Institutional Factors on Unemployment in Visegrad Countries. International Journal of Economic Sciences, Vol. VIII(1), pp. 20-34. , DOI: 10.52950/ES.2019.8.1.002

Gordon, R. J. (1997). The Time-Varying NAIRU and its Implications for Economic Policy. Journal of Economic Perspectives, Vol. 11, No. 1.

Havik, K. et al. (2014). The Production Function Methodology for Calculating Potential Growth Rates \& Output Gaps. Economic Papers 535.

Hromada, E.; Vitasek, S.; Holcman, J.; Schneiderova Heralova, R.; Krulicky, T. Residential Construction with a Focus on Evaluation of the Life Cycle of Buildings. Buildings 2021, 11, 524. https://doi.org/10.3390/buildings11110524

Kadeřábková, B., Jašová, E. (2019). Development of Real Unit Wage Costs on the Macro- and Mezolevel of the Czech Republic. International Journal of Economic Sciences Vol. VIII, No. 2.

Kadeřábková, B., Jašová, E., Holman, R. (2020). Analysis of substitution changes in the Phillips curve in V4 countries over the course of economic cycles. International Journal of Economic Sciences, Vol. IX(2), pp. 39-54. , DOI: 10.52950/ES.2020.9.2.003

Katz, L. F., Krueger, A. B. (1999). The High-Pressure U.S. Labor Market of the 1990s. Brookings Papers on Economic Activity Vol. 30, No. 1: 1-88.

Korenman, S., Neumark, D. (2000). Cohort Crowding and Youth Labor Markets: A Cross-National Analysis. In Youth Employment and Joblessness in Advanced Countries, ed. David G. Blanchflower and Richard B. Freeman. Chicago, University of Chicago Press.

Kotrba, V., Holman, R. (2021). Sports Market as a Data Source for Economics: With Special Emphasis on Betting and Fantasy Sports. International Journal of Economic Sciences, Vol. X(1), pp. 5370. , DOI: 10.52950/ES.2021.10.1.004

Neethu L., Helan, A.P. (2021). The Health Issues and Problems Faced by Returnees from Gulf Countries in Kerala. Intl. J. of Econ. Sci., Vol. X(1), pp. 71-83., 10.52950/ES.2021.10.1.005

Perry, G. L. (1970). Changing Labor Markets and Inflation. Brookings Papers on Economic Activity Vol. 1, No. 3: 411-448. 
Shimer, R. (1999). Why is the U.S. Unemployment Rate So Much Lower? NBER Macroeconomics Annual 13: 11-74.

Shimer, R. (2001). The Impact Of Young Workers On The Aggregate Labor Market. The Quarterly Journal of Economics Vol. 116, No. 3: 969-1007.

Summers, L. H. (1986). Why is the Unemployment Rate So Very High near Full Employment. Brookings Papers on Economic Activity Vol. 17, No. 2: 339-396. 